\title{
Study on the Selection Method of Product Materials based on the Theory of Informed Construction
}

\author{
Xu Fangting, Hu Kang, Zhang Jun, Deng Haobin \\ School of Art \& Design for Wuhan University of Science and Technology \\ Wuhan of Hubei, 30065
}

\begin{abstract}
In order to improve users' overall demand satisfaction and improve the accuracy of material plan selection. Through IT quantitative data analysis theory, using the AHP analytic hierarchy process (AHP) and the quality of QFD house integration method of product material property parameter to calculate, IT is concluded that comprehensive between material properties and design requirements of the user overall satisfaction weight value, providing a scientific reference for the choice of product material. Finally, this method is applied to the selection design of CNC machine tool to verify the feasibility and rationality of this method.
\end{abstract}

Keywords-Product design; CNC machine tools; Theory of informed construction; Material selection; Overall user satisfaction

\section{INTRODUCTION}

In the diversification of the market economy, the product competition more fierce, user-centered present a diversified consumer demand, humanization and personalized features, product material function is no longer a user's sole focus, assessment of the product user has risen to comprehensive consideration of phase [1]. More and more scholars at home and abroad have conducted a lot of researches on the method of product material evaluation. Papagiannidis S et al. [2] applied visual, tactile and olfactory sensory experiences to make selection for follow-up evaluation; Nagamachi [3] proposed the development of product innovation design system based on user demand based on Kansei Engineering; Cooper [4] analyzed the reasons for failure in the new product development process, and put forward the key conditions to ensure the innovation and development of new products. The needs of households. On the basis of the study, the domestic scholar weeks will inscription [5] integrated characters, Analytic Hierarchy Process (AHP), Analytic Hierarchy Process, the AHP), QFD (Quality Function Deployment, QFD) and Usability Testing (Usability Testing) a variety of methods and applied to the product development Process.

However, the ultimate goal of product design is no longer limited to full. Sufficient product functional requirements, the product development process of complex binding problem, such as craft, material, safety, ecological factors has become a big consideration in modern designer for [6]. Aiming at this point, this paper based on the theory of knowledge structure, emphasize the constraint factors in the design process of contact each other, to establish based on the theory of knowledge to construct user oriented design model to overcome in traditional design complexity, is more advantageous to the systematic control and data analysis. Through the optimization algorithm, the user needs and material attributes are combined to realize the product material selection design based on user demand.

\section{THEORY OF INFORMED CONSTRUCTION}

\section{A The information tectonics theory basis of the knowledge structure}

Since the 20th century, with the high integration of digital design, materialization process and manufacturing technology, many design researches and practical developments related to materials have been developed. The theory of informed construction (IT) was first proposed by Oxman R [7] and applied in the research of materials based design. IT has been widely used in structural engineering design, architectural design and other fields. Familiar with the structure design of the positioning to explore new patterns of innovation design, looking for a new model for the design localization, emphasizes from the Angle of material, through systematic data calculation, for the product craft, the relationship between the structure, material and manufacturing for planning, integration and new product forms and structure for product innovation and design, in this new integration, construct the product and the close link between science and technology, to enhance the function of product materials, process and color and material, the communion between to meet the demand of users to provide more design possibilities.

\section{$B$ Informed construction theory (IT) and user-oriented requirements design}

At present, in the traditional design process, through the engineering and technical architect and designer's division of labor cooperation, in the early stages of the product design, the main concept devised by the designer, then by different engineering division for the product structure and material value assessment, in order to complete the processing and manufacturing of products, and then the sale of the products to complete the design and development of the whole product line. Knowledge structure theory is the material design and calculation of the algorithm and user demand oriented design principles, advocating early in the design process for material in harmony with the environment variable method, and emphasizes on the follow-up process, the conversion between design elements [8]. The properties of the material determine the performance of the product structure, and the performance 
of the structure determines the form of the product function, which can transform the design elements through systematic data calculation.

In the stage of the early stage of product design, product structure, form and material in a clear mapping information to guide the design and manufacture, this method of comprehensive consideration of product components can make the whole process of product design and manufacture more rationalization, systematic, their mutual relations are shown in figure 1 .

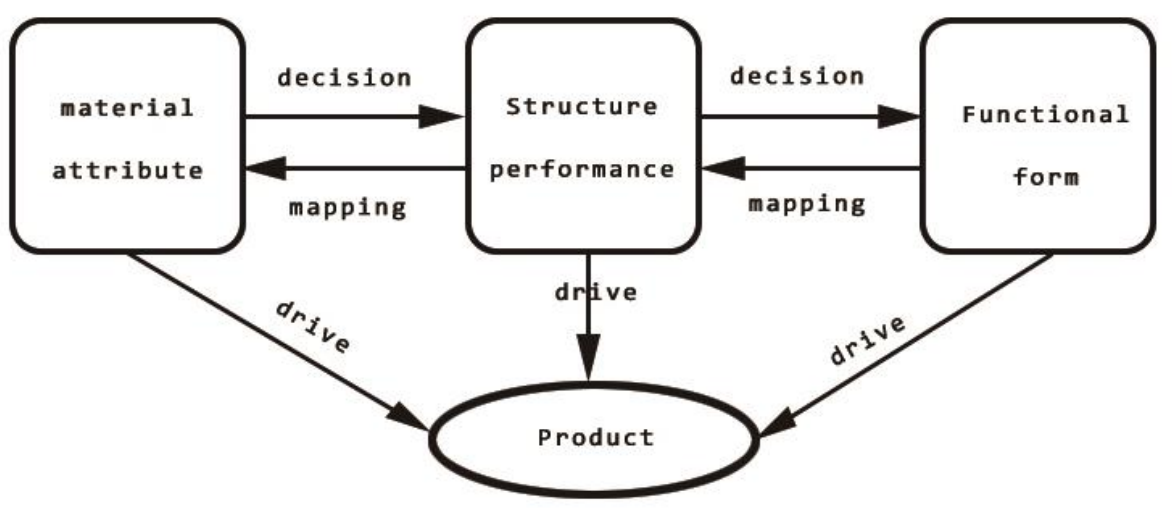

Fig. 1 Product design elements interrelationship diagram

\section{IT THEORETICAL MODEL FRAME CONSTRUCTION}

\section{A Theoretical model of informed construction}

As the product design moves from the idea of product as the center, the designer begins to pay attention to the user's experience and experience of product design [9]. At present, the research on user experience test evaluation in product design field focuses on product modeling, color and man-machine, while there is relatively little research on user visual/touch of materials. According to current situation of the above, can be based on the theory of knowledge structure to carry out the quantitative analysis of data, the integration methods of AHP and QFD to key research of product material, through quantitative data parameters, science to control the whole process of design, in order to improve the accuracy of the design. The IT theoretical model diagram is shown in figure 2 .

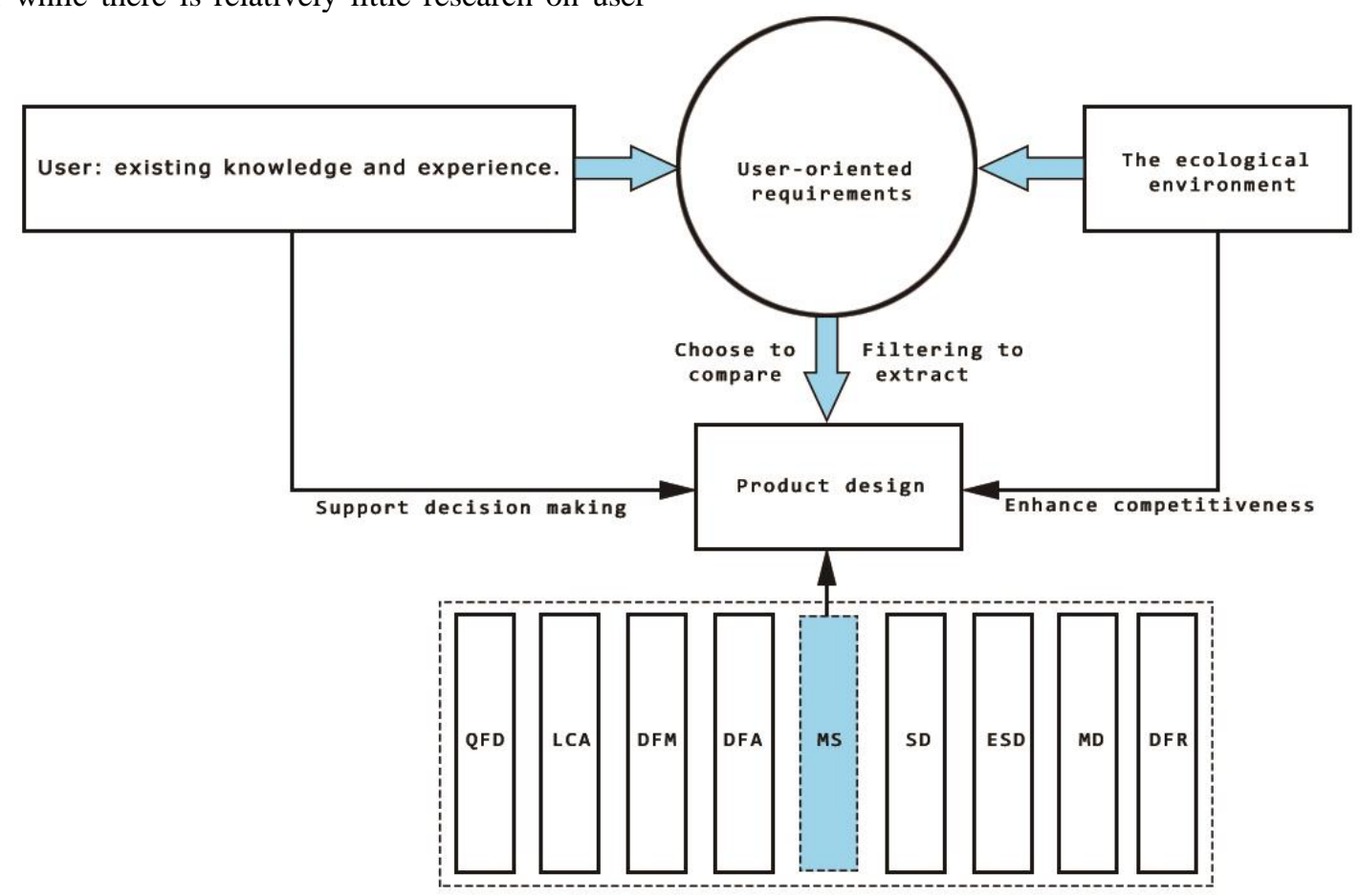

Fig. 2 IT theoretical model diagram 


\section{$B$ The determination of order quality house analysis and} ideal solution

Quality room (QFD) can transform qualitative customer requirements into quantitative design parameters and combine with product design elements [10]. Analytic hierarchy process (AHP) can be used to analyze the judgment of decision-makers, and effectively analyze the non-linear relation between the hierarchy of target criteria [11]. Combined with QFD and AHP, the hierarchical substructure of the problem was established to obtain more scientific and reliable design information. The overall expansion structure of the hierarchical quality room is shown in figure 3 .

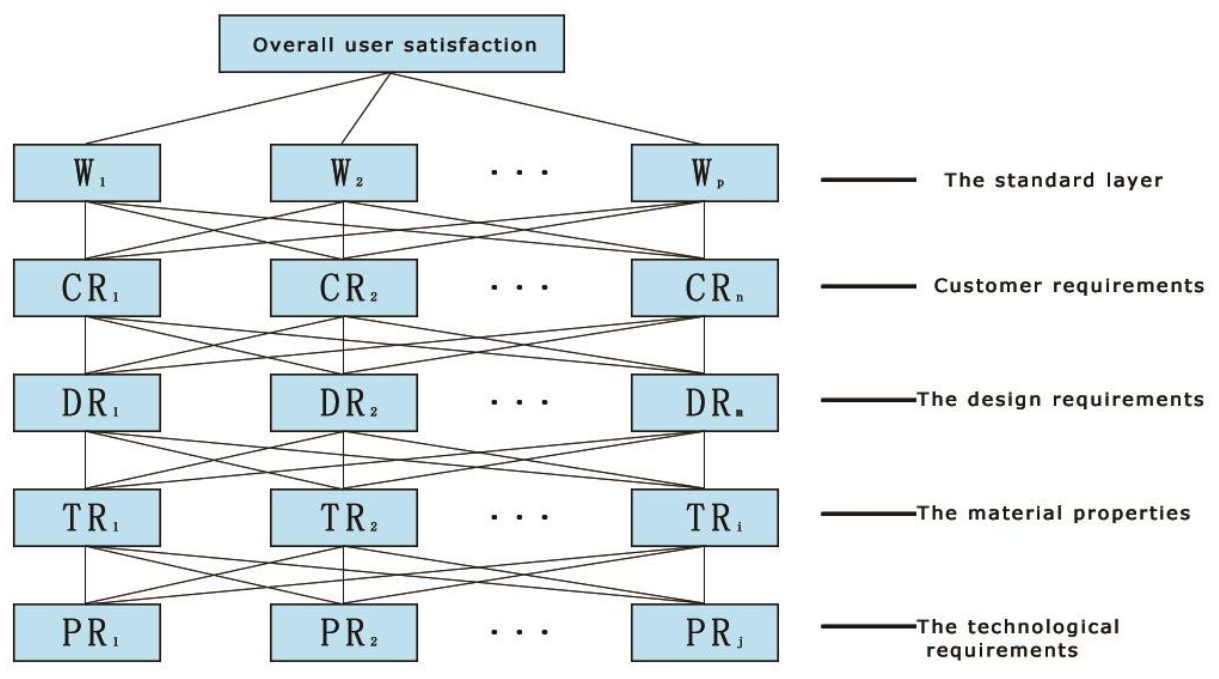

Fig. 3 The general layout of the hierarchical quality room

Based on the theory of IT in the design composition can mutual mapping relations, based on generic algorithm criterion, establish a hierarchical hoq, transforms the design requirements of users for the design of the quantitative parameters, using the AHP method to design based on the overall Customer Satisfaction (Total Customer Satisfaction, TCS) material attribute weights. In the IT theory model, the material attributes should be studied according to the weight of the design requirements criterion, while the analysis of the hierarchical structure mainly focuses on the characteristics and design requirements of the materials.

1) Determine the relative weight of material properties

The hierarchical structure of the material properties and design requirements is constructed, and the matrix relation of each hierarchy is established. The scale values of Saaty [12] are described, and the specific semantics are shown in table 1.

TABLE I SCALE VALUE AND ITS SEMANTIC EXPRESSION

\begin{tabular}{cc}
\hline Scale values & Semantic expression \\
\hline 1 & Two elements are equally important. \\
5 & Element 1 is slightly more important than element 2 Element 1 is much more \\
7 & important than element 2 \\
9 & Element 1 is more important than element 2 \\
The reciprocal of $1 \sim 9$ & Take the median of the above values
\end{tabular}

Establish A judgment matrix between material attributes and design requirements $\mathrm{A}$ :

$$
\boldsymbol{A}=\left[\begin{array}{cccc}
a 11 & a 12 & \cdots & a 1 n \\
\mathrm{a} 21 & \mathrm{a} 22 & \cdots & \mathrm{a} 2 \mathrm{n} \\
\cdots & \cdots & \text { aij } & \cdots \\
\text { an1 } & \text { an2 } & \cdots & \text { ann }
\end{array}\right]
$$

In the formula: aij-The relative weights of the corresponding elements at each level
After establishing the judgment matrix $A$, the relative weight value of material properties can be obtained by using the algorithm:

$$
C i=\frac{1}{n} \sum_{\mathrm{j}=\mathrm{i}}^{\mathrm{n}} \cdot \frac{\mathrm{aij}}{\sum_{k=1}^{n} a k j}(\mathrm{i}=1,2 \cdots, \mathrm{n})
$$

2) Consistency check

Using Saaty [12] rule of experience, the consistency testing of material characteristics and design requirements is carried 
out to ensure the consistency of judgment analysis in the process of sorting weight. When the consistency ratio CR 0.1, it can ensure that the structure precision of the hierarchical quality room is more reasonable.

The consistency index $C I$ can be calculated as:

$$
C I=\frac{\gamma_{\max }-n}{n=1}
$$

In the formula: $\gamma_{\max }-$ - The maximum eigenvalue of the detection matrix A。

Refer to the corresponding average random consistency index $R$, and the specific values are shown in table 2 .

TABLE II AVERAGE RANDOM CONSISTENCY INDEX R

\begin{tabular}{|c|c|c|c|c|c|c|c|}
\hline \multicolumn{8}{|c|}{ Matrix rank } \\
\hline & 1 & 2 & 3 & 4 & 5 & 6 & 7 \\
\hline $\begin{array}{c}\text { Indicators } \\
\mathrm{R}\end{array}$ & 0.00 & 0.00 & 0.52 & 0.89 & 1.12 & 1.26 & 1.36 \\
\hline
\end{tabular}

\section{3) Weight room weight calculation}

Set $\mathrm{m}$ design requirements for DR1, DR2, and... ,DRm, have I material properties TR1, TR2,.., the weight value of the target in $\mathrm{m}$ design requirements is solved by the analytic hierarchy process (ahp) under the fixed criteria, and the weight value of the target in the criteria is denoted as $\mathrm{W}=(\mathrm{W} 1, \mathrm{~W} 2, \ldots$, $\mathrm{Wm}$ ); In order to calculate the corresponding weight value of the attributes of I material and $\mathrm{m}$ design requirements, it is denoted as $\mathrm{V}=(\mathrm{Vm} 1, \mathrm{Vm} 2, \ldots, \mathrm{Vmi})$. In the process, the weight of material attributes that are not bound by the fixed criteria is 0 . The comprehensive weight of the two can be expressed as:

$$
Z_{n}=\sum_{\mathrm{j}=1}^{\mathrm{m}} w_{j} v_{j n}(\mathrm{n}=1,2, \ldots, \mathrm{m})
$$

\section{SCHEME DESIGN}

Taking the design of the shell material of CNC machine tool as an example, the material that conforms to the sheet metal process of $\mathrm{CNC}$ lathe is selected. Combining the theory of knowledge to build relationship between composition, design elements in integrated systematic algorithm calculation, to clear the material properties of nc machine tool and the mapping relationship between design elements, thus improve the user's overall satisfaction.

\section{A Establish a comprehensive design evaluation index system}

In CNC machine tools design elements, in addition to the human, material, shape, color elements, also contains multiple evaluation factors such as social, economic, ecological, multi-level and multi-objective classification index system, is advantageous to the design of the object target elements refining [13]. On the basis of the user oriented knowledge structure model, using AHP method, comprehensive analysis of the numerical control machine tool material properties, through questionnaire survey, similarity detection and clustering analysis.

\section{$B$ Determine the optimal design requirement for material properties}

Use formula (2) and method to calculate the weight value of material design requirements $\mathrm{W} 1, \mathrm{~W} 2, \mathrm{~W} 3, \ldots \mathrm{W} 7$, and the higher the weight value, the higher the overall satisfaction degree of the user to the material attributes, and the specific weight values are shown in table 3 .

TABLE III NUMERICAL CONTROL MACHINE TOOL MATERIAL DESIGN DEMAND WEIGHT VALUE

\begin{tabular}{llllll}
\hline Design requirements & $\begin{array}{l}\text { Modelling } \\
\text { K21 }\end{array}$ & $\begin{array}{l}\text { Standard specification } \\
\text { K22 }\end{array}$ & $\begin{array}{l}\text { Cost } \\
\text { K23 }\end{array}$ & $\begin{array}{l}\text { Identification } \\
\text { K24 }\end{array}$ & $\begin{array}{l}\text { Rationality } \\
\text { K25 }\end{array}$ \\
\hline Weight of demand & 0.234 & 0.479 & 0.579 & 0.226 & 0.397 \\
\hline
\end{tabular}

The attribute judgment matrix of the structural material is corresponding to TR1, TR2, TR3, TR4 and TR5, and the material attribute judgment matrix based on rational $\mathrm{K} 25$ is established based on the scale scale value, as shown in table 4. 
TABLE IV MATERIAL ATTRIBUTE JUDGMENT MATRIX

\begin{tabular}{|c|c|c|c|c|c|}
\hline & security & lightweight & Easy workability & $\begin{array}{l}\text { Green environmental } \\
\text { protection }\end{array}$ & $\begin{array}{l}\text { Maintenance and } \\
\text { recovery }\end{array}$ \\
\hline security & 1 & $1 / 6$ & 2 & 1 & 3 \\
\hline lightweight & $1 / 7$ & 1 & $1 / 3$ & 3 & 5 \\
\hline Easy workability & $1 / 5$ & $1 / 7$ & 1 & $1 / 5$ & 1 \\
\hline $\begin{array}{l}\text { Green environmental } \\
\text { protection }\end{array}$ & 6 & 3 & $1 / 7$ & 1 & 7 \\
\hline $\begin{array}{l}\text { Maintenance and } \\
\text { recovery }\end{array}$ & 1 & 5 & $1 / 3$ & 6 & 1 \\
\hline
\end{tabular}

Similarly, establish a K21, K22, K23, K24, K25 design requirements as the objective principles of material attribute judgment matrix, then the attribute weights in the needs of users design material, CI and consistency index test. According to formula (4), the comprehensive weight $\mathrm{Zn}$ of the two can be calculated, as shown in table 5 .

TABLE V THE COMPREHENSIVE WEIGHT OF DESIGN REQUIREMENTS AND MATERIAL ATTRIBUTES ZN

\begin{tabular}{llllll}
\hline \multicolumn{5}{l}{ The material properties } & \\
\cline { 2 - 6 } & K11 & K12 & K13 & K14 & K15 \\
\hline $\begin{array}{l}\text { The comprehensive weights } \\
\text { Zn }\end{array}$ & 0.357 & 0.182 & 0.223 & 0.196 & 0.273
\end{tabular}

C Design of the selection material for the external protection of CNC machine tools

The CNC machine tool protective material selection to meet green, concise design trends, on the basis of comprehensive index system diagram and the shape features of $\mathrm{CNC}$ machine tools, through six engaged in CNC machine tool industry experts selected 5 kinds of shell protective material. The basic properties of materials are obtained through online data access, as shown in table 6.

TABLE VI BASIC PROPERTIES OF SHEET METAL MATERIAL

\begin{tabular}{|c|c|}
\hline Type & Material properties \\
\hline $\begin{array}{c}\text { Ordinary cold rolled plate } \\
\text { SPCC }\end{array}$ & Easy oxidation, need spray paint, electroplating protection. \\
\hline Galvanized steel SECC & Superior corrosion resistance and decorative, good processing \\
\hline $\begin{array}{l}\text { Hot dip galvanized steel sheet } \\
\text { SGCC }\end{array}$ & Material hardness, ductility wipe, zinc layer thicker, welding poor. \\
\hline Stainless steel SUS301 & Low corrosion resistance, good elasticity. \\
\hline Stainless steel SUS304 & $\begin{array}{c}\text { Corrosion resistance, heat resistance, good mechanical properties, no heat treatment hardening } \\
\text { phenomenon, inelasticity. }\end{array}$ \\
\hline
\end{tabular}

Each base material properties corresponding evaluation, finally be based on user overall satisfaction of the comprehensive weighted grade for market research and expert sheet metal material properties ideal value, as shown in table 7.

TABLE VII IDEAL WEIGHT FOR MATERIAL PROPERTIES

\begin{tabular}{ll}
\hline Type & Ideal weight \\
\hline Ordinary cold rolled plate SPCC & 0.147 \\
Galvanized steel SECC & 0.578 \\
Hot dip galvanized steel sheet SGCC Stainless steel SUS301 & 0.024 \\
Stainless steel SUS304 & 0.137 \\
& 0.879
\end{tabular}

According to the material properties ideal value scores, and found that SUS304 > SECC > $($ SPCC) $>$ SUS301 > SGCC, afterwards outer protective materials for $2 \mathrm{~mm}$ stainless steel SUS304 process processing, build shoulds not be too complicated, increase welding molecular density, more use of the product of the welding assembly. As far as possible, green design should be ensured in product materials and manufacturing, and it can be disassembled and recyclable, so as to control production cost and ensure energy saving. The final scheme renderings are shown in figure 4. 


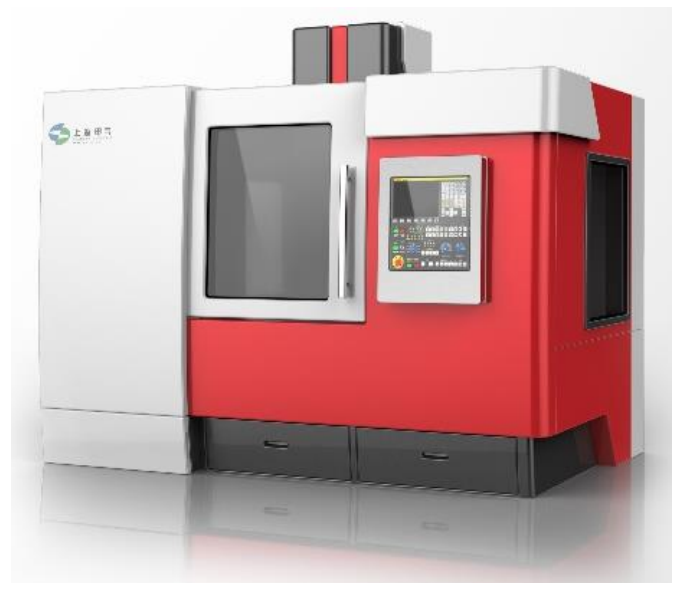

Fig. 4 Scheme renderings

\section{CONCLUSION}

Based on the theory of knowledge structure for the product material selection provides a whole in order to improve the user satisfaction as the breakthrough point of the scientific method, has solved the material properties and design problems of product design requirements between elements, the diversity of market demand better. The deficiency lies in the design problem and the mathematical complexity of the design process, which involves the uncertainty of the numerical sampling, so it is necessary to further explore this method.

\section{REFERENCES}

[1] Tang Bangbei, Guo Gang, Xia Jingjun. Research on the methods of industrial design materials based on user's visual/tactile experience [J]. Journal of mechanical engineering, 2013,53 (3) : 162-:172.

[2] PAPAGIANNIDIS S, SEE-TO E, BOURLAKIS M. Virtual test-driving: The impact of simulated products on purchase intention $[\mathrm{J}]$. Journal of Retailing and Consumer Services,2014, 21(5):877-887.

[3] Nagamachi M. Kansei engineering as a powerful consumer oriented technology for product development [J]. Applied Ergonomics,2002,33(1): 289-294.

[4] Cooper A. About face 3: The essentials of interaction design [J]. MIT Press Mental Neurology, 2007, 18(1):10-21.

[5] Zhou Jiangming. Research and application of new product development methods based on user [D]. Beijing: tsinghua university, 2013.

[6] Chen Guodong, Chen Siyu, Wang Jun et al. Multi-objective optimization of product configuration for composite image [J]. China mechanical engineering, 2015,26 (20) : 2763-:2770.

[7] Oxman R. Informed tectonics in material-based design [J]. Design Studies,2012,33(5):427-455.

[8] Oxman N. Material-based design computation [D]. Cambridge: Massachusetts Institute of Technology, 2010.

[9] Luo Shijian, Zhu Shangshang, Ying Fangtian et al. Research status and progress of user tacit knowledge in product design [J]. Computer integrated manufacturing system, 2010,16 (4) : 673-688.

[10] Zhang Lei, Ge Weiming, Li Lingling et al. Industrial design definition, category, method and development trend review [J]. Mechanical design, 2013, (8) : 97-101.

[11] Qi Bing, Sun Xiaoming. Research on fuzzy evaluation method for numerical control machine tool design based on AHP [J]. Machine tool and hydraulic, 2014,42(1):165-168.

[12] Jaiswal R K, Thomas T, Galkate R V et al. Watershed prioritization using Satty's AHP based decision support for soil conservation measures [J]. Water Resources Management,2014,28(2):475-494.

[13] Zhang Suojiang, Zhang Xiangping, Li Chunshan. Research and prospect of the synthesis and design of green process system $[\mathrm{J}]$. Journal of process engineering, 2005, 5 (5):580-590. 